mean ideas lost for good under present-day hectic conditions. It is, then, in the industrialist's interest to come to an understanding, so far as practicable, with his scientific personnel, on mutual intercourse. The use of a typist should by no means be restricted to purely clerical work. How many of Wordsworth's gems would have been lost to posterity were it not for sister Dorothea capturing the flowing words. If typists are not denied to directors and if poets find them useful, then surely the research scientist while manipulating should be encouraged to declaim his readings, his observations, his trains of thought to a shorthand typist seated within unobtrusive earshot.

Finally, it is possible that when engaged on pressing priority work, men will be tempted to work so fast that their readings are not properly recorded. This tendency to relapse into scrap-of-paper habits should be resisted firmly. One never knows when the story as a whole may not be wanted.

Holt's Crest,

Fordcombe, Kent, and

Guy's Hospital Medical School.

\section{Science and Education}

SCIENCE in relation to education has been prominent in NATURE for many months, but one aspect of the matter seems to me to deserve more attention : the social and historical setting of science. Sir Richard Gregory said" : "One reason why few men of science care to take an active part in politics, is that they do not feel able to effect [such] a transfer of their trained habits of thought" to the consideration of social and political problems. It certainly seems true that very few men of science can effect this transfer; nearly always judgment is heavily influenced by some bias, necessarily subjective. Moreover, this applies equally to men of letters, to men of business, to men in every walk of life. Therefore, we must think, not only of fitting the scientific man to play a conscious part in history, but also of giving the scientific outlook to the historian and the classic. When these men of the 'humanities' view social development with the same critical objectivity as the scientific man, they will be less likely to misguide us. The historian particularly needs the scientific attitude; for example, it is incredible that H. A. L. Fisher could write in 1936 ("History of Europe", p. 1207) on Hitlerite Germany : "Some items, such as the Second Punic War with England and the war of revenge on France, are no longer regarded as likely to be remunerative. Far more promising as a means of augmenting the territory of the Third Reich is the expedient of the plebiscite."

Now, I suggest that the inability of the man of science to carry his trained habits of thought into other fields, and the entire lack of the scientific attitude on the part of others, is due to the isolation of the several subjects in the schools during the formative years. The error of the schools is not that they give too much time to any one subject, but that they fail to integrate them all into a single whole. How can this be remedied? The progress of science is contained in the advance of history, and itself helps to shape that advance, affecting every branch of human culture. On this ground I make the following suggestions : (1) The approach to science should be historical, the fundamental principles being studied in their historical order, against a background of contemporary social development. Apart from the basic reason for this, any branch of science becomes more real, and so more interesting and educative, if studied in this way. (2) To effect the above there must be complete correlation between the science class, the history class, the literature class, etc., the several syllabuses being planned as parts of one whole, bringing out the mutual actions between the various forms of social activity, in such a way that the student applies the scientific method of thought to all his studies. (3) Modern ideas on science, not always more difficult to understand than the concepts of classical science, should be included, impressing on the student that no theory, however well established it may seem, can be final. (4) Science must be understood to extend beyond the confines of physics, chemistry and biology, to embrace all social phenomena, involving the introduction of elementary instruction on statistics. In the study of human behaviour, the student should acquire the same attitude of mind as in his study of physical or chemical phenomena; theory must be tested by experience, both in the continuum of social history and the laboratory.

There should be no difficulty in finding time for such a programme, if it be recognized that the achievement is not to be a vast store of factual knowledge, but an understanding of principles and methods, and appreciation of the part played by science in shaping human society, and the ability to find factual knowledge when it is required. Least of all should we move towards vocational teaching in the primary or secondary school.

Clearbrook,

Yelverton,

Devon.

${ }^{2}$ NATURE, March 7, 1942, p. 261.

\section{Prof. A. R. Forsyth}

MAY I correct Prof. Chapman on two minor points (NATURE, 150, 49; 1942)? Forsyth's Calcutta lectures, published in 1914, were on the theory of functions of two complex variables. His treatise on differential geometry, published in 1912, that is, before he went to Calcutta, is described in the preface as consisting of the substance of lectures delivered during his tenure of the Sadlerian professorship at Cambridge. In his retirement Forsyth produced, not two treatises, but three, the third, which appeared in two volumes in 1935 with the somewhat misleading title of "Intrinsic Geometry of Ideal Space", being an extension to $n$ dimensions of the analysis which for three dimensions and for four had been developed in earlier works.

I would not impertinently praise Prof. Whittaker, but as I am writing I should like to express the indebtedness of all for his masterly discussion of the decline of Forsyth's reputation. We all know that fifty years ago Forsyth's name stood internationally for English pure mathematics; we needed to be told that it stood worthily.

University,

E. H. Nevirue.

Reading. 